University of Nebraska - Lincoln

DigitalCommons@University of Nebraska - Lincoln

\title{
$2-2013$
}

\section{Behavioural Salinity Preferences of Juvenile Green Sturgeon Acipenser medirostris Acclimated to Fresh Water and Full- Strength Salt Water}

\author{
J. B. Poletto \\ University of California, Davis, jpoletto2@unl.edu \\ D. E. Cocherell \\ University of California, Davis, decocherell@ucdavis.edu \\ A. P. Klimley \\ University of California, Davis, apklimley@ucdavis.edu \\ J. J. Cech Jr. \\ University of California, Davis, jjcech@ucdavis.edu \\ N. A. Fangue \\ University of California, Davis, nafangue@ucdavis.edu
}

Follow this and additional works at: https://digitalcommons.unl.edu/natrespapers

Part of the Aquaculture and Fisheries Commons, Marine Biology Commons, Natural Resources and Conservation Commons, Natural Resources Management and Policy Commons, and the Other Environmental Sciences Commons

Poletto, J. B.; Cocherell, D. E.; Klimley, A. P.; Cech, J. J. Jr.; and Fangue, N. A., "Behavioural Salinity Preferences of Juvenile Green Sturgeon Acipenser medirostris Acclimated to Fresh Water and FullStrength Salt Water" (2013). Papers in Natural Resources. 1276.

https://digitalcommons.unl.edu/natrespapers/1276

This Article is brought to you for free and open access by the Natural Resources, School of at DigitalCommons@University of Nebraska - Lincoln. It has been accepted for inclusion in Papers in Natural Resources by an authorized administrator of DigitalCommons@University of Nebraska - Lincoln. 
Published in Journal of Fish Biology 82:2 (February 2013), pp. 671-685; doi: 10.1111/jfb.12023

Copyright (C 2013 J. B. Poletto, D. E. Cocherell, A. P. Klimley, J. J. Cech Jr., and N. A. Fangue. Journal of Fish Biology published by the Fisheries Society of the British Isles and Wiley. Used by permission. Submitted May 11, 2012; accepted November 13, 2012; published online January 29, 2013.

\title{
Behavioural Salinity Preferences of Juvenile Green Sturgeon Acipenser medirostris Acclimated to Fresh Water and Full-Strength Salt Water
}

\author{
J. B. Poletto, D. E. Cocherell, A. P. Klimley, J. J. Cech Jr., and N. A. Fangue
}

Department of Wildlife, Fish and Conservation Biology, University of California, Davis, Davis, California, USA

Corresponding author - J. B. Poletto, University of California, Department of Wildlife, Fish and Conservation Biology, One Shields Avenue, Davis, CA 95616, USA, telephone 1-530-752-3203, email jbpoletto@ucdavis.edu

\begin{abstract}
To quantify the salinity preference of juvenile green sturgeon Acipenser medirostris, two groups of A. medirostris [140 days post hatch (dph); total length $(L \mathrm{~T}) 38.0-52.5 \mathrm{~cm}$ ] were acclimated to either near fresh water (mean \pm S.E. salinity $=3.2 \pm 0.6$ ) or full-strength salt water $(34.1 \pm 1.2$ ) over 8 weeks. Following acclimation, the two groups were divided into experimental and control groups, where experimental $A$. medirostris from both freshwater and saltwater acclimations were individually introduced (200-220 dph) into a rectangular salinity-preference flume (maximum salinity gradient: 5-33). Control $A$. medirostris were presented with only their acclimation water (fresh water or salt water) on both sides of the flume. It was demonstrated that A. medirostris acclimated to both salt water and fresh water spent a significantly greater amount of time on the side of the testing area with the highest salinity concentration $(P<0.05$ and $P<0.001$, respectively) while control $A$. medirostris spent an equal amount of time on each side of the flume. These findings indicate that juvenile $A$. medirostris are not only capable of detecting salt water within the first year of their lives but perhaps are actively seeking out saline environments as they move through a watershed. Establishing $A$. medirostris salinity preferences provides a better understanding of the early life history of this threatened species, shedding light on possible outmigration timing.
\end{abstract}


Keywords: anadromy, behavior, environmental factor, outmigration, preference flume

\section{Introduction}

The green sturgeon Acipenser medirostris Ayres 1854 is a long-lived anadromous fish inhabiting waters of the Pacific Ocean region of North America. Sturgeons are members of the subclass Chondrostei and order Acipenseridae, a group of evolutionarily ancient fishes that branched off from the more-derived teleosts over 200 million years ago (Moyle, 2002). These ancient fishes are slow to reach sexual maturity and do not spawn annually, characteristics that place them at risk for population decline. The A. medirostris population comprises two genetically distinct population segments (DPSs; Israel et al., 2004) that differ in spawning ground locations. The northern DPS spawns principally in the Rogue River in Oregon and the Klamath River in California, although both the Umpqua and Eel Rivers may contribute to the spawning population (Erickson et al., 2002; NOAA, 2005). The southern DPS currently spawns only in the Sacramento River, California (Israel et al., 2004). Because of the restricted spawning grounds of the southern DPS as well as habitat degradation and evidence of declining population numbers, the southern DPS was listed by National Marine Fisheries Division of NOAA in 2006 as "Threatened" under the Endangered Species Act.

While many sturgeon species are known to be semi-anadromous, spending much of their life in brackish and estuarine environments, A. medirostris are believed to be one of the most truly anadromous (Doroshov, 1985; Allen \& Cech, 2007), spending a significant portion of their life in a marine environment. Because of their anadromy, A. medirostris are highly migratory and undertake long migrations between their freshwater natal spawning grounds and the ocean. Acipenser medirostris make seasonal migrations while in the Pacific Ocean; in the autumn, they move north along the continental shelf off California to British Columbia, overwintering in waters off Vancouver Island before undertaking a return migration in the spring (Lindley et al., 2008). In spring, mature, ripe, southern DPS adults migrate upstream to spawning sites in the main stem of the Sacramento River (Heublein et al., 2009). Adults seek out fresh waters with deep, cool pools containing cobble as substratum on which to spawn (M. Thomas, pers. comm.). Adults may remain in the upper reaches of the rivers during the summer before returning to the ocean in autumn (Erickson \& Webb, 2007; Heublein et al., 2009). After hatching, juvenile A. medirostris may remain in freshwater systems for 3 years or less before entering the ocean (Nakamoto \& Kisanuki, 1995), entering salt water at a relatively young age (Allen et al., 2009a). Juveniles then spend the next several years growing and developing in the ocean until they reach sexual maturity and return to spawn, around 14-16 years of age (Van Eenennaam et al., 2006). The specific timing of these spawning migrations, and particularly the juvenile outmigration from riverine fresh waters into estuarine and saline environments is poorly understood. As far as is known, no previous studies have focused on the behavior of juvenile A. medirostris in response to differences in environmental salinities, and their cryptic early life history remains poorly characterized in this regard.

As juvenile A. medirostris undertake their outmigration from the upper reaches of freshwater river systems, they encounter waters of increasing salinity and eventually reach fullstrength salt water. The physiological adjustments that are made by A. medirostris as they 
enter waters with increasing salinities have been investigated in different age classes (Allen et al., 2009b, 2011), and are characterized by changes in cellular gill and kidney structure that function in support of osmoregulation. Allen \& Cech (2007) found that $77 \%$ of $A$. medirostris as young as 100 days post hatch $(\mathrm{dph})$ were able to tolerate the transfer into salt water, while A. medirostris aged $170 \mathrm{dph}$ could do so without any reported mortalities, suggesting that the ontogeny of saltwater tolerance occurs sometime during this developmental period. Despite these and other investigations into the physiological responses of exposure to waters with increasing salinity (Sardella \& Kültz, 2009), the behavior of $A$. medirostris in response to variable salinity has not been studied. Additionally, while water flow and environmental temperature are thought to be the primary environmental stimuli that mediate their outmigration, based on telemetry data correlated with records from the U.S. Geological Survey station (Erickson et al., 2002), salinity may be another important cue that helps guide juvenile $A$. medirostris to the ocean.

Laboratory-determined behavioral preferences can be an important tool in understanding an animal's naturally occurring behavior, particularly for fish species where field observation or collection is difficult and data for threatened species are needed (Chan et al., 1997). These data are obtained using preference devices, such as shuttleboxes (Mortensen et al., 2007; Meager \& Utne-Palm, 2008; Serrano et al., 2010) or flumes (Chan et al., 1997; Kemp et al., 2005; Dixson et al., 2008), in which animals are given an opportunity to detect and respond to environments with different abiotic characteristics (Chen et al., 2008). If the animals are actively sensing environmental cues, they may seek out one environment versus another, providing insight into the preferences of the animal at that particular life stage. For example, Crean et al. (2005) evaluated the behavioral salinity preferences of the European eel Anguilla anguilla (L. 1758) in three different developmental stages to aid in the characterization of the upstream migration of this catadromous species. Similarly, juvenile A. medirostris behavioral preferences and responses to waters with different salinities may provide critical information into their behavioral patterns as they begin their outmigration, perhaps allowing establishment of a timeframe during which A. medirostris enter saline environments. The goal of this study was to quantify the behavioral salinity preferences of juvenile A. medirostris acclimated to two different water salinities: A. medirostris that had been transitioned into full-strength salt water and $A$. medirostris reared in fresh water that had never been exposed to full-strength salt water.

\section{Materials and Methods}

\section{Acipenser medirostris}

F2 A. medirostris from UC Davis broodstock (northern DPS) were spawned in April 2010 [following the methodology described in Van Eenennaam et al. (2001)] and reared at $18^{\circ} \mathrm{C}$ at the UC Davis Center for Aquatic Biology and Aquaculture in round fiberglass tanks (815l) with continuous flows of aerated, nonchlorinated fresh water from a dedicated well. The inflowing water [mean \pm S.E. dissolved oxygen $(\mathrm{DO})=8.5 \pm 1.0 \mathrm{mg} \mathrm{O}_{2} 1^{-1}, 0$ salinity] produced a current of $<10 \mathrm{~cm} \mathrm{~s}^{-1}$ in each tank. Acipenser medirostris were fed daily to satiation with semi-moist pellets (Rangen, Inc.; www.rangen.com) and eventually weaned onto a dry pelleted diet (SilverCup, Nelson \& Sons, Inc.; www.silvercup.com) at c. $60 \mathrm{dph}$. All 
handling, care and experimental procedures used were reviewed and approved by the UC Davis Institutional Animal Care and Use Committee (IACUC).

\section{Acclimation and Transport}

Juvenile A. medirostris were randomly assigned to either the freshwater or saltwater acclimation group ( $n=20$ in each group, freshwater or saltwater $A$. medirostris) when they reached an age of $140 \mathrm{dph}$, an age somewhat older than that of $A$. medirostris previously shown to be able to tolerate acclimation to full-strength salt water with limited mortality (100 dph; Allen et al., 2009a). Saltwater A. medirostris were acclimated at salinity increases of 5 per day until water salinity concentration reached full-strength salt water (33). After saltwater concentration reached 33 for a full $24 \mathrm{~h}$, both freshwater and saltwater A. medirostris were transported to the Bodega Marine Laboratory (BML) in Bodega Bay, California, in aerated coolers. At BML, each acclimation group was placed in separate 15001 flowthrough tanks. Freshwater A. medirostris were held at BML in well-water delivered from a dedicated, nonchlorinated system (water conditions listed in Table I). Saltwater A. medirostris were held in water delivered via the BML water intake system from the Pacific Ocean. The tanks were kept outdoors, partially covered and exposed to natural photoperiod $\left(38^{\circ} 19^{\prime} \mathrm{N}\right)$. Acipenser medirostris were held at these water conditions for 8 weeks prior to the start of the experiments. Salinity preference experiments were conducted over 3 weeks on A. medirostris $200-220 \mathrm{dph}$. There were no significant differences in fork length $(L \mathrm{~F}, \mathrm{~cm})$, total length $(L \mathrm{~T}, \mathrm{~cm})$ or mass $(\mathrm{g})$ of $A$. medirostris between acclimation groups (Table I).

Table I. Acclimation conditons and sizes of individuals in the two acclimation group of juvenile Acipenser medirostris. Values shown are mean \pm S.E.

\begin{tabular}{lccccccc}
\hline $\begin{array}{l}\text { Acclimation } \\
\text { group }\end{array}$ & $\begin{array}{c}\text { Temperature } \\
\left({ }^{\circ} \mathrm{C}\right)\end{array}$ & $\begin{array}{c}\mathrm{DO} \\
\left(\mathrm{mg} \mathrm{O}_{2}{ }^{-1}\right)\end{array}$ & Salinity & $L \mathrm{~F}(\mathrm{~cm})$ & $L_{\mathrm{T}}(\mathrm{cm})$ & Mass $(\mathrm{g})$ & $n$ \\
\hline Fresh water & $15.6 \pm 0.6$ & $7.2 \pm 0.6$ & $3.2 \pm 0.6$ & $40.6 \pm 0.6$ & $43.7 \pm 0.7$ & $355.1 \pm 18.1$ & 19 \\
Salt water & $12.5 \pm 0.6$ & $8.2 \pm 0.2$ & $34.1 \pm 1.2$ & $39.1 \pm 0.6$ & $43.6 \pm 0.6$ & $358.2 \pm 15.2$ & 19 \\
\hline
\end{tabular}

$\mathrm{DO}$, dissolved oxygen concentration; $L \mathrm{~F}$, fork length; $L \mathrm{~T}$, total length; $n$, sample size

\section{Salinity Preference Flume}

The rectangular salinity preference flume (Fig. 1) was constructed of painted fiberglass and Plexiglas (www.plexiglas.com; $185 \mathrm{~cm}$ long $\times 85 \mathrm{~cm}$ wide $\times 19 \mathrm{~cm}$ deep). The upstream portion of the flume contained a water input area with a $10 \mathrm{~cm} \times 425 \mathrm{~cm}$ spillover chamber that "pushed" water into a separate $10 \mathrm{~cm} \times 42.5 \mathrm{~cm}$ chamber with a raised bottom to force water flow through a series of $10 \mathrm{~cm}$ long flow straighteners constructed from $2.5 \mathrm{~cm}$ diameter polyvinyl chloride pipe. This water input system was partitioned in half to independently deliver separate water streams to the two sides of the preference flume. The $A$. medirostris testing area was $70 \mathrm{~cm}$ long $\times 85 \mathrm{~cm}$ wide and was separated from the upstream water input system and downstream drainage pipes via front and rear wire-mesh screens $\left(0.635 \mathrm{~cm}^{2} \mathrm{mesh}\right)$. The rectangular testing area was partially divided by a partition of clear Plexiglas that was mounted against the rear screens and extended $33 \mathrm{~cm}$ into the testing area. An additional rectangular $(21 \mathrm{~cm}$ wide $\times 15 \mathrm{~cm}$ long) divider attached to the front 
screens separated the testing area into two distinct regions. Preliminary investigations revealed that the dividers were necessary to minimize mixing of water flows between the two sides of the flume. These dividers created a $22 \mathrm{~cm}$ long opening through which $A$. medirostris were able to move freely, occupying one side of the flume or the other. The entire preference flume was shrouded with shade cloth to prevent possible experimenter influence, and a camera (8 mm Canon Hi-Fi Stereo Camcorder; www.canonusa.com) was mounted directly over the center of the testing area to record fish behaviors during an experiment without disturbance. Water was pumped into the flume system from two separate water reserve tanks (each $55 \mathrm{~cm} \times 35 \mathrm{~cm} \times 152 \mathrm{~cm}, 170$ l) located beneath the preference flume. Water depth in the flume during experiments was $16 \mathrm{~cm}$. Return flows from the preference flume drained back into the reserve tank from which it was originally pumped. During experiments, additional water was pumped into the reserve tanks from either the BML saltwater delivery system (mean \pm S.E. $=34.1 \pm 1.2$ ) or a 25001 freshwater tank (mean \pm S.E. $=3.2 \pm 0.6$ ) that held aerated fresh water overnight. This system recirculated a small amount of water through the preference flume while continuously providing a source of new water into each reserve tank to maintain the appropriate salinity gradient for the duration of the preference experiments. Excess water from the reserve tanks drained to an external water discharge system. 


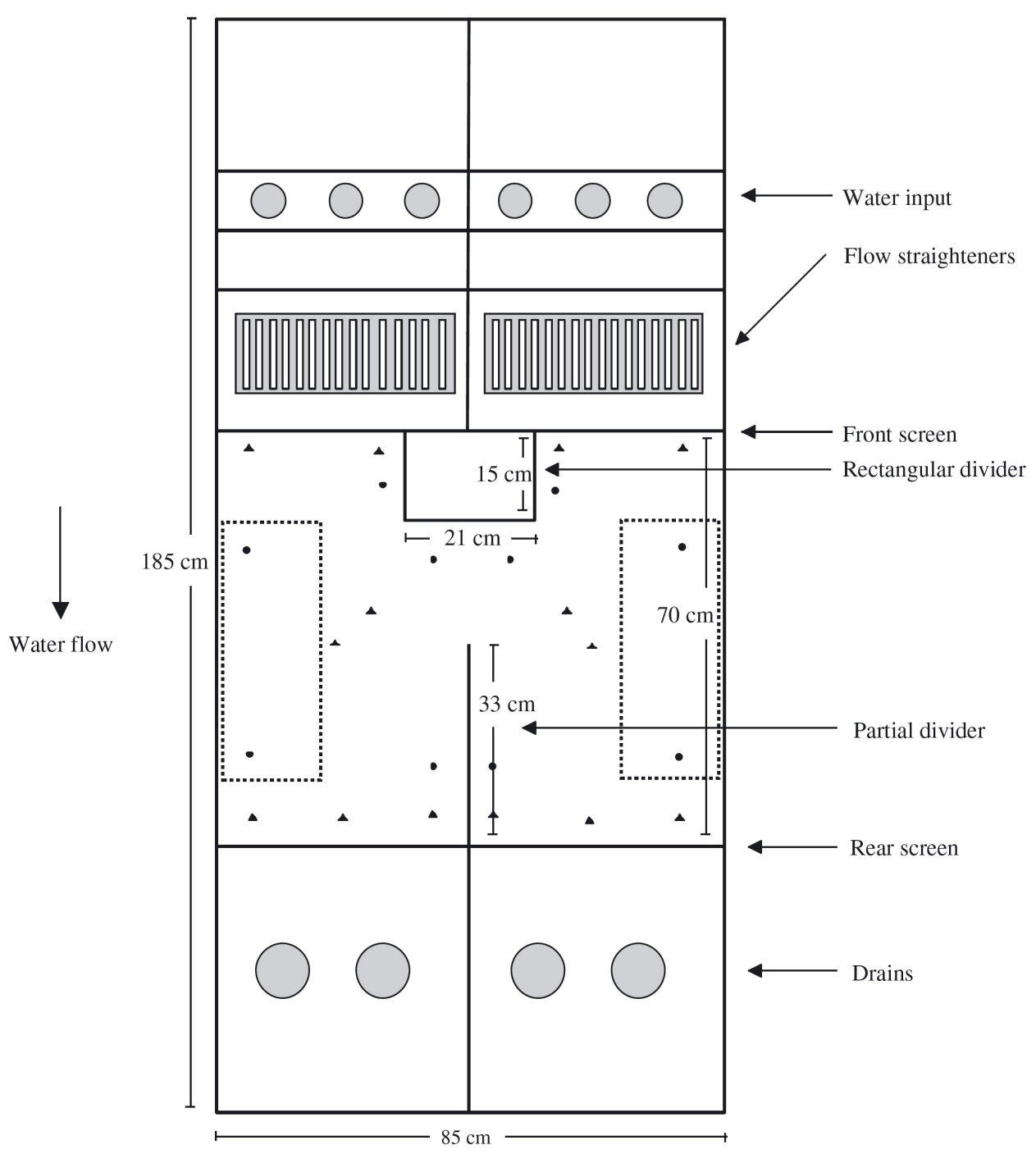

Figure. 1. Overhead view of the salinity preference flume. Water input and drainage areas were separated from the testing area with front and back wire-mesh screens $\left(0.635 \mathrm{~cm}^{2}\right)$. The testing area includes a partial divider and a rectangular divider used to reduce mixing between waters with different salinities. $\bullet$, indicate where salinity measurements were taken; $\boldsymbol{\Lambda}$, indicate where flow measurements were taken; dashed boxes, location where salinity measurements used in analyses of preferred salinity concentrations of experimental Acipenser medirostris were taken. Drawn to scale. 
Once established, the gradient (shown in Fig. 2) created distinct environments with respect to salinity and was stable over time. To confirm this, salinity measurements were taken in multiple locations throughout the experiments. Water samples were taken at 10 locations within the testing area (five on each side) via micro-bore tubing (Tygon, S-54-HL; www.processsystems.saint-gobain.com) and attached syringes (18 gauge, $5 \mathrm{ml}$ ) to verify the establishment of the salinity gradient. Salinity measurements were taken twice ( 5 and $15 \mathrm{~min}$ ) following the start of the exposure period (described later) using a calibrated, handheld refractometer (SPER Scientific, 300011; www.sperdirect.com). To further confirm the stability of the salinity gradient, four measurements (two on each side) were taken near the end of the exposure period ( $25 \mathrm{~min}$ following start). Additionally, source water velocities necessary to maintain a stable salinity gradient were established during preliminary experiments and held constant throughout all subsequent experiments. Velocity measurements were taken at seven locations on each side of the testing area (Fig. 1) using a portable water current flow-meter (Marsh McBirney Model 201D; www.hach.com/mmi). During the experiments, water temperature and DO were measured using a multiprobe meter (YSI, model 85; www.ysi.com), while light levels were measured using a light meter (Extech Instruments, Model 401025; www.extech.com) on each side of the testing area at the start and the end of each exposure period.

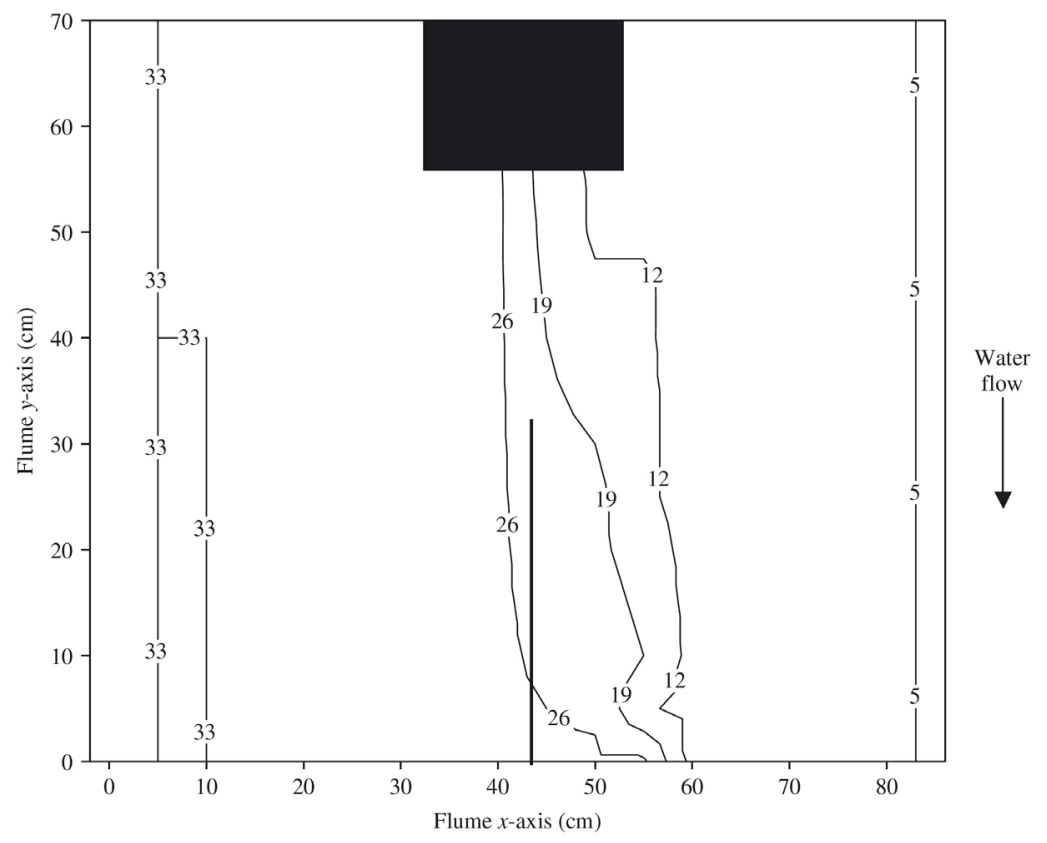

Figure 2. Contour plot of the salinity gradient within the testing area during preference experiments. Contour lines show salinity values across the flume. Salinities ranged from 5 to 33 , and the gradient changed roughly linearly between these contour lines. The visualized salinity gradient was modeled from salinity measurements taken from 10 locations within the flume during the exposure period of each trial. The $\mathbf{a n d}-$ within the gradient represent the dividers used to separate the water flow and divide the testing area. The salinity regimes presented were significantly different between the two sides $(P<0.001)$. 


\section{Experimental Protocol}

Following acclimation, the freshwater and saltwater groups were further divided into control (tested in the flume under acclimation conditions) and experimental $A$. medirostris (tested in the presence of the salinity gradient), creating four groups: freshwater controls $(n=7)$, saltwater controls $(n=8)$, freshwater experimental A. medirostris $(n=12)$, and saltwater experimental $A$. medirostris $(n=11)$. Each behavioral salinity preference experiment consisted of a $30 \mathrm{~min}$ acclimation period during which $A$. medirostris were exposed to their acclimation salinity, immediately followed by a $30 \mathrm{~min}$ period during which $A$. medirostris were exposed to either control or experimental salinity gradients. Acipenser medirostris were placed into the testing area of the flume individually, and placement of individuals into either the left or right side of the testing area was randomized. After the $30 \mathrm{~min}$ flume acclimation period, the water pumps were started to establish the salinity gradient, marking the initiation of the exposure period. For control A. medirostris, no salinity difference was created across the flume, and for experimental $A$. medirostris, a salinity difference across the flume was created with the side of saltwater inflow randomized for each experiment. Two experimental A. medirostris remained on the same side of the testing area they occupied when the exposure period began, thereby not experiencing the salinity difference between the two sides, and were not included in the analysis. Following each experiment, A. medirostris were removed from the flume, measured for length $(L \mathrm{~T}$ and $L \mathrm{~F}, \mathrm{~cm})$ and mass (g), marked on their dorsal fin with a notch to indicate previous participation in the experiment and returned to their acclimation tank. There were no post-experimental mortalities.

\section{Behavioral Measurements and Data Analysis}

To quantify A. medirostris movement, the number of times an individual crossed the central divider (counted as each time the full body of an A. medirostris passed the partition) was recorded. Behavioral salinity preferences of juvenile A. medirostris were quantified by measuring the residence time $(\mathrm{min})$ on each side of the testing area. The barrier crossings and residence times were recorded using JWatcher v. 1.0 (www.jwatcher.ucla.edu; Blumstein et al., 2006) during the $30 \mathrm{~min}$ exposure period to ensure that $A$. medirostris experienced no difficulty in passing the partition and exhibited no (nonsalinity related) preference between the two sides of the flume. Individual A. medirostris barrier crosses and residence times on each side were then averaged within the four test groups for the exposure period. No differences in water quality variables (DO, temperature and light level) were detected over time during the exposure period (e.g., start versus end), so measurements were averaged for each side of the flume within each of the four control or experimental groups. Preliminary behavioral analysis revealed that all $A$. medirostris spent the majority of the experimental period in one of the two areas of the flume (one area on each side, indicated by dashed boxes on Fig. 1). To most accurately represent the salinity of the water in which individuals spent the majority of their time, the average salinity measurements taken from only these areas were used in the analyses of salinity. The salinity difference across the flume was quantified by comparing the salinity measurements taken from these areas across all time points during the exposure period for the experimental A. medirostris exposed to the gradient in each acclimation group. To visualize the salinity gradient, a salinity contour plot was created in SigmaPlot v. 1.2 (www.sigmaplot.com). Data were analyzed 
using statistical analysis systems (SAS; www.sas.com) 9.1.3 and SigmaStat 3.0 (www.sigmaplot .com) software packages. Partition crossings, DO, temperature, light level measurements, and water salinity measurements for each side of the flume were analyzed nonparametrically with a Kruskal-Wallis one-way ANOVA on ranks with a subsequent Dunn's pairwise comparisons analysis. Residence times were analyzed parametrically with missingmeasures ANOVAs and subsequent Tukey pairwise comparisons tests to accommodate A. medirostris that were not included in the analysis. Statistical significance was considered at $\alpha \leq 0.05$.

\section{Results}

\section{Water Conditions}

Water quality measurements and light levels observed during the trials are summarized in Table II. There were no significant differences in temperature, DO, or light levels between the left and right sides of the testing area for control A. medirostris from the saltwater and freshwater acclimation groups. Similarly, there were no significant differences in temperature, DO, or light levels for experimental $A$. medirostris between the saltwater side of the testing area and the side through which "fresh" water was presented (because of the mean salinity concentration, reported later, this side is referred to as the "brackish water" side). There were differences in water velocity (range $=0.06-0.21 \mathrm{~m} \mathrm{~s}^{-1}$ ) within each side of the testing area that were necessary to maintain a salinity gradient. The flow regime on each side of the testing area was effectively and consistently the same on each side. Average water velocity was not significantly different between the two sides of the testing area across all experiments (left versus right, $0.16 \pm 0.03$ versus $0.15 \pm 0.03 \mathrm{~m} \mathrm{~s}^{-1}$, mean \pm S.E.; $t$-test: $t=0.138$, d.f. $=12, P>0.05$ ). Because water from the same source was pumped into each side of the testing area for the control $A$. medirostris, there was no salinity difference between them. The salinity regimes presented to experimental $A$. medirostris were significantly different (Kruskal-Wallis test, $H=271.9$, d.f. $=3, P<0.001$ ). The salinity measurements from the two areas described earlier (indicated by dashed boxes in Fig. 1) had a mean \pm S.E. of $9.3 \pm 0.2$ on the brackish side and $29.2 \pm 0.2$ on the saltwater side. The salinity gradient can essentially be described as two large rectangular streams in which the water was largely brackish occupying one side of the testing area with a similar region on the opposite side of the flume that was predominately salt water (Fig. 2). The region between these two bodies of water was characterized by a salinity gradient in which salinities changed roughly linearly between contour lines. The A. medirostris were rarely stationary in the region near the center divider; rather they used it only as a conduit to pass between the saltwater and the brackish areas. The salinity profiles across the flume were statistically indistinguishable between the two acclimation groups; neither the salinity presented on the brackish side of the flume nor that presented on the saltwater side of the flume differed significantly between the two acclimation groups exposed to the salinity gradient (Dunn's test, $Q=1.97, P>0.05 ; Q=2.39, P>0.05$, respectively), demonstrating that $A$. medirostris from both groups were challenged with the same choice in environmental salinity. Additionally, there was no significant interaction between the salinity gradient and the time at which the measurement was recorded during the experiment (ANOVA, $F_{2.2}=1.46, P>0.05$ ), 
indicating that the gradient was maintained throughout the $30 \mathrm{~min}$ experimental period and was stable with respect to time.

Table II. Salinity preference flume temperature, dissolved oxygen (DO), and light levels during experiments. Values shown are mean \pm S.E. For each acclimation group (fresh water and salt water), left and right side flume values are shown for control Acipenser medirostris, while values for the brackish side and saltwater side of the testing area are given for experimental $A$. medirostris.

\begin{tabular}{|c|c|c|c|c|c|c|c|c|c|}
\hline & & \multicolumn{4}{|c|}{ Fresh water } & \multicolumn{4}{|c|}{ Salt water } \\
\hline & & $\begin{array}{c}\text { Temper- } \\
\text { ature } \\
\left({ }^{\circ} \mathrm{C}\right)\end{array}$ & $\begin{array}{c}\mathrm{DO} \\
\left(\mathrm{mg} \mathrm{O}_{2} \mathrm{l}^{-1}\right)\end{array}$ & $\begin{array}{c}\text { Light } \\
(\times 1001 x)\end{array}$ & $n$ & $\begin{array}{c}\text { Temper- } \\
\text { ature } \\
\left({ }^{\circ} \mathrm{C}\right)\end{array}$ & $\begin{array}{c}\mathrm{DO} \\
\left(\mathrm{mg} \mathrm{O}_{2} \mathrm{l}^{-1}\right)\end{array}$ & $\begin{array}{c}\text { Light } \\
(\times 1001 x)\end{array}$ & $n$ \\
\hline \multirow[t]{2}{*}{ Control } & $\begin{array}{l}\text { Right } \\
\text { side }\end{array}$ & $15.8 \pm 0.2$ & $9.4 \pm 0.4$ & $312.0 \pm 65.4$ & 7 & $13.7 \pm 0.2$ & $8.8 \pm 0.1$ & $217.9 \pm 42.5$ & 8 \\
\hline & $\begin{array}{l}\text { Left } \\
\text { side }\end{array}$ & $15.8 \pm 0.2$ & $9.4 \pm 0.4$ & $288.6 \pm 59.6$ & & $13.7 \pm 0.2$ & $8.8 \pm 0.1$ & $212.6 \pm 49.7$ & \\
\hline \multirow[t]{2}{*}{$\begin{array}{l}\text { Experi- } \\
\text { mental }\end{array}$} & $\begin{array}{l}\text { Brackish } \\
\text { side }\end{array}$ & $14.9 \pm 0.2$ & $8.7 \pm 0.2$ & $253.3 \pm 36.7$ & 12 & $14.8 \pm 0.3$ & $8.6 \pm 0.1$ & $247.9 \pm 32.2$ & 11 \\
\hline & $\begin{array}{l}\text { Saltwater } \\
\text { side }\end{array}$ & $13.9 \pm 0.1$ & $9.1 \pm 0.1$ & $243.9 \pm 34.2$ & & $13.8 \pm 0.1$ & $9.2 \pm 0.3$ & $228.1 \pm 25.6$ & \\
\hline
\end{tabular}

$n$, sample size

\section{Behavioral Preferences}

As an index of movement, the number of partition crosses was assessed during the exposure period (presented in Table III). Although control A. medirostris from both acclimation groups showed a trend toward more partition crossings than did those of the experimental A. medirostris, this trend was not significant. Mean residence times spent by A. medirostris on the two sides of the testing area, however, differed among the two treatment groups and the controls (ANOVA, $F_{5,70}=7.471, P<0.001$ ). Neither freshwater nor saltwater control A. medirostris preferred to occupy one side of the flume compared with the other, and the two acclimation groups were, therefore, combined into one "control" group for this analysis. To quantify salinity preference, the amount of time spent on each side of the flume was measured in the two acclimation groups exposed to the salinity gradient. Saltwateracclimated A. medirostris exposed to the gradient spent a significantly greater amount of time on the saltwater side of the flume compared to the amount of time spent on the brackish side (Fig. 3; $24.1 \pm 2.9$ min versus $5.9 \pm 2.9$ min; mean \pm S.E.; Tukey's test, $q=6.9, P<$ 0.001 ). These A. medirostris spent roughly $80 \%$ of the $30 \mathrm{~min}$ exposure period on the saltwater side of the flume, regardless of which physical side of the testing area this represented. Interestingly, the freshwater experimental A. medirostris also demonstrated a clear preference for the saltwater side of the flume compared to the brackish side $(20.7 \pm 2.2 \mathrm{~min}$ versus $9.1 \pm 2.2 \mathrm{~min}$; mean \pm S.E.; Tukey's test, $q=4.6, P<0.05$ ), spending almost $70 \%$ of the exposure period in waters with the higher salinity. Experimental juvenile $A$. medirostris from both acclimation groups spent the majority of the exposure period in the large rectangular streams of water on each side of the flume (Fig. 2), each with relatively constant salinity (described earlier). Control A. medirostris also favored the streams of water near 
the edges of the testing area but did not spend significantly different amounts of time on one side of the flume compared to the other (left versus right, $17.6 \pm 2.4$ min versus $12.2 \pm$ 2.3 min; mean \pm S.E.; Tukey's test, $q=2.4, P>0.05$ ).

Table III. Number of partition crossings made by Acipenser medirostris during the experimental period. Values shown are means \pm S.E. The number of times control A. medirostris crossed the $33 \mathrm{~cm}$ partition during the experimental period was greater than that for experimental $A$. medirostris for both acclimation groups, although neither difference was statistically significant $(P>0.05$ for both comparisons).

\begin{tabular}{lccccc}
\hline & \multicolumn{2}{c}{ Control } & & \multicolumn{2}{c}{ Experimental } \\
\cline { 2 - 3 } \cline { 5 - 6 } \cline { 5 - 6 } Freshwater A. medirostris & Number of crosses & $n$ & & Number of crosses & $n$ \\
Saltwater $A$. medirostris & $16.7 \pm 4.0$ & 7 & & $7.9 \pm 1.4$ & 12 \\
\hline
\end{tabular}

$n$, sample size

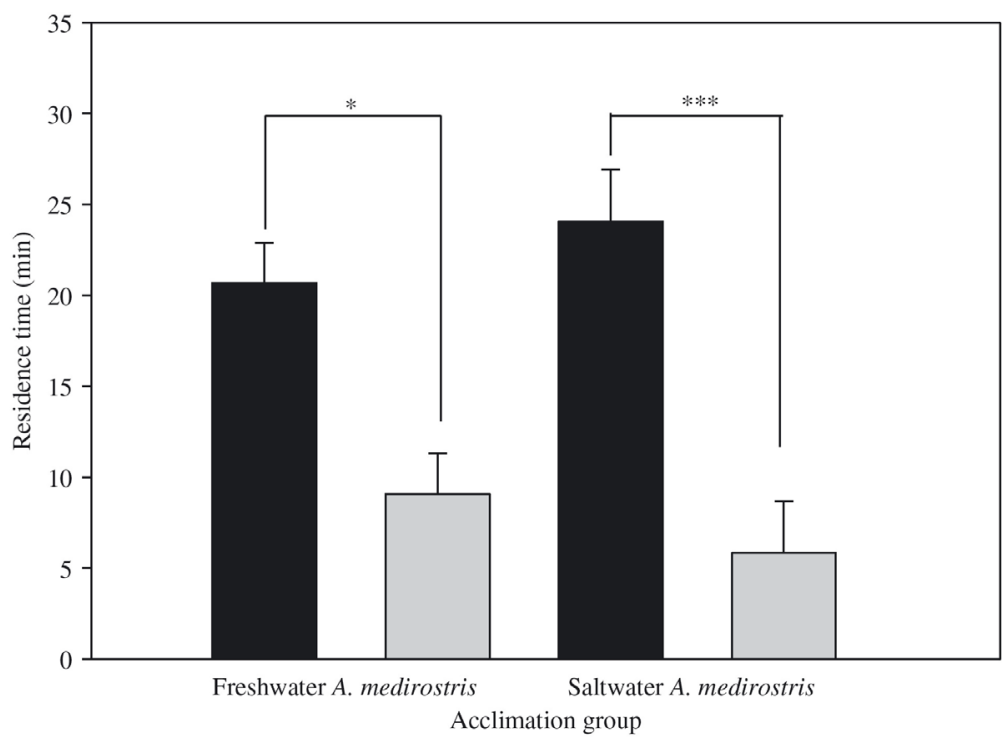

Figure 3. Residence time of experimental Acipenser medirostris on the saltwater versus brackish side of the testing area. Both the saltwater and freshwater experimental $A$. medirostris spent a significantly greater amount of time on the saltwater side compared with the brackish side during the exposure period, as indicated $\left({ }^{*} P<0.05 ;{ }^{* *} P<0.001\right)$.

$\mathbf{\square}$, the amount of time $A$. medirostris spent on the saltwater side of the testing area; $\square$, the amount of time spent on the brackish side. Values shown are mean \pm S.E. residence times.

\section{Discussion}

The results of this study show that juvenile A. medirostris of c. 200-220 dph, regardless of acclimation salinity, show a strong preference for saline waters, suggesting that they may enter saline environments within their first year of life. Juvenile A. medirostris acclimated to fresh water, with no previous exposure to salt water, preferred to reside within the 
environment with higher salinity when given a choice between brackish and salt water. These results indicate that juvenile $A$. medirostris in the wild may actively seek out saline environments as early as 6 months of age as they begin their outmigration to the ocean. Saltwater adaptation in salmonids generally occurs prior to saltwater exposure, during a period termed "smoltification" when endogenous hormones mediate rapid morphological, physiological, and behavioral changes (Hoar, 1988; Björnsson \& Bradley, 2007; McCormick, 2009, 2011). This process, however, is less well understood in sturgeon species; recent research indicates that some physiological changes associated with saltwater adaptation are triggered by exposure to hyperosmotic environments, while others are most probably regulated by endogenous factors (Allen et al., 2009a). The results of this study also suggest that an endogenous mechanism might play a role in saltwater preparation, as freshwateracclimated A. medirostris with no previous exposure to salt water displayed a clear preference for waters with a greater salinity. In addition, the finding that saltwater-acclimated A. medirostris also preferred high salinity suggests that once these animals reach salt water they choose to remain there.

These results agree with previous studies that showed $A$. medirostris of this age, previously exposed only to fresh water, are saltwater tolerant (Allen et al., 2009a). Recently, a study evaluating the ontogeny of saltwater tolerance in A. medirostris demonstrated that while A. medirostris were able to survive a brief exposure $(72 \mathrm{~h})$ to full-strength salt water at $134 \mathrm{dph}$, long-term survival (28 days) in salt water was achieved by age 7 months (Allen et al., 2011). Additionally, studies using Ba:Ca to determine entry into saline environments showed that wild $A$. medirostris entered waters with greater salinity, such as estuaries, as early as age 6 months (Allen et al., 2009b). This suggests that as juveniles move downstream and experience increasing salinity gradients, they will pursue more saline environments. If juvenile $A$. medirostris are indeed actively seeking out waters with greater salinity concentrations in the wild as they outmigrate, these salinity differences could represent an important sensory cue in guiding their movements.

Behavioral preference methodology, such as that utilized in this study, allows valuable insight into the behaviors naturally exhibited by juvenile $A$. medirostris. It is possible, however, that the experimental design and experimental flume features necessary to generate a salinity gradient influenced the results. For example, because the exposure period was only $30 \mathrm{~min}$, A. medirostris were unable to make the full complement of biochemical adjustments known to be associated with the transitions between freshwater and saltwater phenotypes (which take days to weeks to complete depending on the physiological variable measured), and a longer exposure time to the salinity gradient could result in different behavioral responses as these A. medirostris remodeled their physiology (Hoar, 1988; Evans, 2010). What these data show is that $A$. medirostris were able to perceive and interpret salinity differences at a sensory and neural level and make choices about which environment to reside based on the perceived differences in salinity.

It is also possible, although unlikely, that subtle differences in water flow across the flume affected the behavior of $A$. medirostris. Water flows in the preference flume ranged from $0.06 \mathrm{~m} \mathrm{~s}^{-1}$ near the center dividers of the flume to $0.21 \mathrm{~m} \mathrm{~s}^{-1}$ along the flume margins and at the inflow screens. To put these velocities into perspective, water flows $<0.30 \mathrm{~m} \mathrm{~s}^{-1}$ present no swimming challenge to A. medirostris of this size in assessments of critical 
swimming speed $\left(U_{\text {crit) }}\right.$. Trials to evaluate $U_{\text {crit }}$ in $A$. medirostris are initiated at this velocity as it is the lowest flow velocity at which the majority of A. medirostris will consistently swim to maintain position within experimental flumes (D. E. Cocherell, unpublished data). Careful measures were taken to make sure that the flow regime on each side of the flume matched that on the other side. The differences seen within the testing area on one side were effectively mirrored on the other, creating no difference in flow velocities or flow regimes between the two sides. Increased water flow downstream is a correlate of outmigration in A. medirostris (Erickson et al., 2002), and higher flows near the sides of the flumes could explain why A. medirostris selected these areas. Alternatively, A. medirostris may have preferred the stable salinities near the sides of the flume rather than occupying the central gradient. Regardless, because A. medirostris experienced the same water velocities and areas of stable salinity on each side of the testing area, preference for the saltwater side indicates that $A$. medirostris were making the choice based on salinity. Indeed, only $A$. medirostris that sampled both sides of flume during the exposure period were used in the analyses, strengthening the conclusion that residence times reflect a behavioral preference for salinity.

Compared with other anadromous Acipenser and Scaphirhynchus species, juvenile $A$. medirostris are able to successfully osmoregulate in full-strength salt water at perhaps the earliest age (Allen \& Cech, 2007), indicating that there may be species-specific differences in the amount of time anadromous sturgeon species spend rearing in freshwater habitats. Despite potential differences in the specific timing of life-history stages, previous studies on other Acipenser species have indicated patterns in salinity preferences of juveniles similar to those of A. medirostris. Young-of-the-year Atlantic sturgeon Acipenser oxyrinchus Mitchill 1815 preferred waters with a salinity of 8 versus 1 (Niklitschek \& Secor, 2010). Similarly, European sturgeon Acipenser sturio L. 1758 entered estuarine environments in their first year of life and entered the ocean as early as their second year (Rochard et al., 2001). These studies collectively indicate that juvenile, anadromous Acipenser species, including $A$. medirostris, seek out waters with greater salinity early in life.

Because of its anadromous life history, A. medirostris may gain selective advantages from entering salt water during early life stages. Enhanced growth is often cited as a primary benefit of migrating into salt water, but the effects of salt water on growth can be intricate and dynamic (Boeuf \& Payan, 2001). The effects of salinity on growth are mediated by changes in metabolic rate, food intake, and food conversion efficiency as well as by endogenous hormonal mechanisms (Boeuf \& Payan, 2001). While measuring growth variables in relation to salinity was not the primary objective, no differences in growth between A. medirostris acclimated to fresh water or full-strength salt water were detected. This could be due to slight differences in acclimation temperatures between groups (Table I; saltwater A. medirostris, $12.5 \pm 0.6^{\circ} \mathrm{C}$ versus freshwater $A$. medirostris, $15.6 \pm 0.6^{\circ} \mathrm{C}$ ) caused by the dependence of the acclimation waters on Pacific Ocean conditions (salt water) or the BML well-water delivery system (fresh water), rather than a reflection of salinity influences on growth. It has long been thought that anadromous fish species that migrate into salt water early in life evolved this life-history strategy to maximize their growth by exploiting an enhanced productivity of the ocean, as compared to freshwater systems (Gross et al., 1988). Regardless, the osmoregulatory demands placed on the fishes can be great, 
and there is a positive correlation of age and body size of fishes and their ability to osmoregulate. Therefore, the exact timing of entry into salt water may depend on species-specific characteristics as well as a trade-off between the advantages of maximizing growth early in life and the physiological demands of transition into salt water. Because behavior is influenced by underlying physiological traits and demands as well as exogenous stimuli, investigations into preference can help determine the timing of this process.

Behavioral salinity preferences are not only informative in the context of understanding early life history and physiological optima but also important to consider in managed ecosystems where maintaining salinities that support natural distributions of juvenile $A$. medirostris throughout the environment is a concern. Southern DPS A. medirostris reside within the San Francisco Bay estuary and watershed, which is the site for one of the most extensive water management projects to date (Knowles, 2002). This plan includes regulation of water flow through reservoirs and pumping stations, affecting salinity throughout the estuary (Kimmerer, 2002). While the effect of salinity management on San Francisco Bay fishes is not particularly well documented, changes in environmental salinity have been shown to shift the distribution and abundance of fish assemblages (Baptista et al., 2010), including the composition of fish communities (Thiel et al., 1995). Greenwood (2007) found that fish and invertebrate occurrence and community structure changed rapidly along salinity gradients throughout two estuaries in Florida. Similarly, the distribution of juvenile $A$. medirostris could be altered throughout the watershed and estuary depending upon how water flow is managed and salinities are affected throughout the year. Future studies should focus on evaluating the behavioral preferences of juveniles at earlier life stages to identify when their preference for salt water emerges. These data can be used by water and fisheries resources managers working to balance natural $A$. medirostris recruitment with other water-related needs.

Acknowledgments - We thank the Yurok Tribe for acquisition of the sturgeon broodstock and J. Van Eenennaam and S. Doroshov for breeding them; P. Lutes and E. Hallen of UC Davis Center for Aquatic Biology and Aquaculture for fish care; and K. Brown, P. Smith, and the staff of the Aquatics Resource Group at the Bodega Marine Laboratory for tank space and technical assistance. We would also like to thank two anonymous reviewers and a JFB editor for their helpful comments in improving this manuscript. J.B.P. was supported through an NSF Graduate Student Fellowship, and the research was funded by the California Department of Fish and Game's Ecosystem Restoration Program (agreement \#E0783004 to A.P.K., N.A.F., and J.J.C.).

\section{References}

Allen, P. J. \& Cech, J. J. Jr. (2007). Age/size effects on juvenile green sturgeon, Acipenser medirostris, oxygen consumption, growth, and osmoregulation in saline environments. Environmental Biology of Fishes 79, 211-229. doi: 10.1007/s10641-006-9049-9

Allen, P. J., Hobbs, J. A., Cech, J. J. Jr., Van Eenennaam, J. P. \& Doroshov, S. I. (2009a). Using trace elements in pectoral fin rays to assess life history movements in sturgeon: estimating age at initial seawater entry in Klamath River green sturgeon. Transactions of the American Fisheries Society 138, 240-250. doi: 10.1577/T08-061.1 
Allen, P. J., Cech, J. J. Jr. \& Kültz, D. (2009b). Mechanisms of seawater acclimation in a primitive anadromous fish, the green sturgeon. Journal of Comparative Physiology B 179, 903-920. doi: 10.1007/ s00360-009-0372-2

Allen, P. J., McEnroe, M., Forostyan, T., Cole, S., Nicholl, M. M., Hodge, B. \& Cech, J. J. Jr. (2011). Ontogeny of salinity tolerance and evidence for seawater-entry preparation in juvenile green sturgeon, Acipenser medirostris. Journal of Comparative Physiology B 181, 1045-1062. doi: 10.1007/ s00360-011-0592-0

Baptista, J., Matinho, F., Dolbeth, M., Viegas, I., Cabral, H. \& Pardal, M. (2010). Effects of freshwater flow on the fish assemblage of the Mondego estuary (Portugal): comparison between drought and non-drought years. Marine and Freshwater Research 61, 490-501. doi: 10.1071/MF09174

Björnsson, B. T. \& Bradley, T. M. (2007). Epilogue: past successes, present misconceptions and future milestones in salmon smoltification research. Aquaculture 273, 384 -391. doi: 10.1016/j.aquaculture.2007.10.020

Boeuf, G. \& Payan, P. (2001). How should salinity influence fish growth? Comparative Biochemistry and Physiology C 130, 411-423. doi: 10.1016/S1532-0456(01)00268-X

Chan, M. D., Dibble, E. D. \& Kilgore, K. J. (1997). A laboratory examination of water velocity and substrate preference by age-0 gulf sturgeons. Transactions of the American Fisheries Society 126, 330333. doi: 10.1577/1548-8659(1997)126<0330:ALEOWV>2.3.CO;2

Chen, S. X., Hong, W. S., Su, Y. Q. \& Zhang, Q. Y. (2008). Microhabitat selection in the early juvenile mudskipper Boleophthalmus pectinirostris (L.). Journal of Fish Biology 72, 585-593. doi: 10.1111/ j.1095-8649.2007.01723.x

Crean, S. R., Dick, J. T. A., Evans, D. W., Rosell, R. S. \& Elwood, R. W. (2005). Survival of juvenile European eels (Anguilla anguilla), transferred among salinities, and developmental shifts in their salinity preference. Journal of Zoology 266, 11-14. doi: 10.1017/S0952836905006539

Dixson, D. L., Jones, G. P., Munday, P. L., Planes, S., Pratchett, M. S., Srinivasan, M., Syms, C. \& Thorrold, S. R. (2008). Coral reef fish smell leaves to find island homes. Proceedings of the Royal Society B 275, 2831-2839. doi: 10.1098/rspb.2008.0876

Doroshov, S. I. (1985). The biology and culture of sturgeon. In Recent Advances in Aquaculture, Vol. 2 (Muir, J. \& Roberts, R., eds), pp. 251-274. London: Croom Helm.

Erickson, D. L. \& Webb, M. A. H. (2007). Spawning periodicity, spawning migration, and size at maturity of green sturgeon, Acipenser medirostris, in the Rogue River, Oregon. Environmental Biology of Fishes 79, 255-268. doi: 10.1007/s10641-006-9072-x

Erickson, D. L., North, J. A., Hightower, J. E., Weber, J. \& Lauck, L. (2002). Movement and habitat use of green sturgeon Acipenser medirostris in the Rogue River, Oregon, USA. Journal of Applied Ichthyology 18, 565-569. doi: 10.1046/j.1439-0426.2002.00403.x

Evans, T. G. (2010). Co-ordination of osmotic stress responses through osmosensing and signal transduction events in fishes. Journal of Fish Biology 76, 1903-1925. doi: 10.1111/j.1095-8649.2010.02590.x

Greenwood, M. F. D. (2007). Nekton community change along estuarine salinity gradients: can salinity zones be defined? Estuaries and Coasts 30, 537-542. doi: 10.1007/BF03036519

Gross, M. R., Coleman, R. M. \& McDowall, R. M. (1988). Aquatic productivity and the evolution of diadromous fish migration. Science 239, 1291-1293. doi: 10.1126/science.239.4845.1291

Heublein, J. C., Kelly, J. T., Crocker, C. E., Klimley, A. P. \& Lindley, S. T. (2009). Migration of green sturgeon, Acipenser medirostris, in the Sacramento River. Environmental Biology of Fishes 84, 245258. doi: $10.1007 / \mathrm{s} 10641-008-9432-9$

Hoar, W. S. (1988). The physiology of smolting salmonids. In Fish Physiology, Vol. XIB (Hoar, W. S. \& Randall, D., eds), pp. 275-343. New York, NY: Academic Press. 
Israel, J. A., Cordes, J. F., Blumberg, M. A. \& May, B. (2004). Geographic patterns of genetic differentiation among collections of green sturgeon. North American Journal of Fisheries Management 24, 922-931. doi: 10.1577/M03-085.1

Kemp, P. S., Gessel, M. H. \& Williams, J. G. (2005). Seaward migrating subyearling chinook salmon avoid overhead cover. Journal of Fish Biology 67, 1381-1391. doi: 10.1111/j.1095-8649.2005.00833.x

Kimmerer, W. J. (2002). Physical, biological, and management responses to variable freshwater flow into the San Francisco estuary. Estuaries 25, 1275-1290. doi: 10.1175/1520-0485(2002)032<3003:SA FIVO $>2.0 . \mathrm{CO} ; 2$

Knowles, N. (2002). Natural and management influences of freshwater inflows and salinity in the San Francisco Estuary at monthly to interannual scales. Water Resources Research 38, 1289. doi: 10.1029/ 2001WR000360

Lindley, S. T., Moser, M. L., Erickson, D. L., Belchik, M., Rechisky, E. L., Kelly, J. T., Heublein, J. \& Klimely, A. P. (2008). Marine migration of North American green sturgeon. Transactions of the American Fisheries Society 137, 182-194. doi: 0.1577/T07-055.1

McCormick, S. D. (2009). Evolution of the hormonal control of animal performance: insights from the seaward migration of salmon. Integrative and Comparative Biology 46, 408-422. doi: 10.1093/icb/icp044

McCormick, S. D. (2011). The hormonal control of osmoregulation in teleost fish. In Encyclopedia of Fish Physiology: From Genome to Environment, Vol. 2 (Farrell, A. P., ed), pp. 1466-1473. San Diego, CA: Academic Press.

Meager, J. J. \& Utne-Palm, A. C. (2008). Effect of turbidity on habitat preference of juvenile Atlantic cod, Gadus morhua. Environmental Biology of Fishes 81, 149-155. doi: 10.1007/s10641-007-9183-z

Mortensen, A., Ugedal, O. \& Lund, F. (2007). Seasonal variation in the temperature preference of Arctic charr (Salvelinus alpinus). Journal of Thermal Biology 32, 314-320. doi: 10.1016/j.jtherbio.2007.03.004

Moyle, P. B. (2002). Inland Fishes of California. Berkeley, CA: University of California Press.

Niklitschek, E. J. \& Secor, D. H. (2010). Experimental and field evidence of behavioural habitat selection by juvenile Atlantic Acipenser oxyrinchus oxyrinchus and short-nose Acipenser brevirostrum sturgeons. Journal of Fish Biology 77, 1293-1308. doi: 10.1111/j.1095-8649.2010.02748.x

Rochard, E., Lepage, M., Dumont, P., Tremblay, S. \& Gazeau, C. (2001). Downstream migration of juvenile European sturgeon Acipenser sturio L. in the Gironde Estuary. Estuaries 24, 108-115. doi: $10.2307 / 1352817$

Sardella, B. A. \& Kültz, D. (2009). Osmo- and ionoregulatory responses of green sturgeon (Acipenser medirostris) to salinity acclimation. Journal of Comparative Physiology B 179, 383-390. doi: 10.1007/ s00360-008-0321-5

Serrano, X., Grosell, M. \& Serafy, J. E. (2010). Salinity selection and preference of the grey field and laboratory observations. Journal of Fish Biology 6, 1592-1608. doi: 10.1111/j.1095-8649.2010.02585.x

Thiel, R., Sepúlveda, A., Kafemann, R. \& Nellen, W. (1995). Environmental factors as forces structuring the fish community of the Elbe Estuary. Journal of Fish Biology 46, 47-69. doi: 10.1111/j.10958649.1995.tb05946.x

Van Eenennaam, J. P., Webb, M. A. H., Deng, X., Doroshov, S. I., Mayfield, R. B., Cech, J. J. Jr., Hillemeier, D. C. \& Willson, T. E. (2001). Artificial spawning and larval rearing of Klamath River green sturgeon. Transactions of the American Fisheries Society 130, 159-165. doi: 10.1577/1548-8659(2001) 130<0159:ASALRO $>2.0 . C O ; 2$

Van Eenennaam, J. P., Linares, J., Doroshov, S. I., Hillemeier, D. C., Willson, T. E. \& Nova, A. A. (2006). Reproductive conditions of the Klamath River green sturgeon. Transactions of the American Fisheries Society 135, 151-163. doi: 10.1577/T05-030.1 


\section{Electronic References}

Blumstein, D. T., Evans, C. S. \& Daniel, J. C. (2006). JWatcher. Available at www.jwatcher.ucla.edu (last accessed 20 November 2011).

Nakamoto R. J. \& Kisanuki, T. T. (1995). Age and growth of Klamath River green sturgeon (Acipenser medirostris). U.S. Fish and Wildlife Service Report 93-FP-13. Available at www.krisweb.com/biblio/ klamath_usfws_nakamotoetal_1995_sturgeon.pdf (last accessed 30 July 2012).

NOAA (2005). Green sturgeon (Acipenser medirostris) status review update. Available at www.nmfs .noaa.gov/pr/pdfs/statusreviews/greensturgeon_update.pdf (last accessed 30 July 2012). 